\title{
An improved delivery system for bladder irrigation
}

\author{
This article was published in the following Dove Press journal: \\ Therapeutics and Clinical Risk Management \\ 22 September 2010 \\ Number of times this article has been viewed
}

\author{
Mohammad K Moslemi' \\ Mojtaba Rajaei ${ }^{2}$ \\ 'Department of Urology, ${ }^{2}$ Kamkar \\ Hospital, School of Medicine, Qom \\ University of Medical Sciences, Qom, \\ Iran
}

Introduction: Occasionally, urologists may see patients requiring temporary bladder irrigation at hospitals without stocks of specialist irrigation apparatus. One option is to transfer the patient to a urology ward, but often there are outstanding medical issues that require continued specialist input. Here, we describe an improved system for delivering temporary bladder irrigation by utilizing readily available components and the novel modification of a sphygmomanometer blub. This option is good for bladder irrigation in patients with moderate or severe gross hematuria due to various causes.

Materials and methods: In this prospective study from March 2007 to April 2009, we used our new system in eligible cases. In this system, an irrigant bag with $1 \mathrm{~L}$ of normal saline was suspended $80 \mathrm{~cm}$ above the indwelled 3-way Foley catheter, and its drainage tube was inserted into the irrigant port of the catheter. To increase the flow rate of the irrigant system, we inserted a traditional sphygmomanometer bulb at the top of the irrigant bag. This closed system was used for continuous bladder irrigation (CBI) in patients who underwent open prostatectomy, transurethral resection of the prostate (TURP), or transurethral resection of the bladder (TURB). This high-pressure system is also used for irrigation during cystourethroscopy, internal urethrotomy, and transurethral lithotripsy. Our 831 eligible cases were divided into two groups: group 1 were endourologic cases and group 2 were open prostatectomy, TURP, and TURB cases. The maximum and average flow rates were evaluated. The efficacy of our new system was compared prospectively with the previous traditional system used in 545 cases.

Results: In group 1, we had clear vision at the time of endourologic procedures. The success rate of this system was $99.5 \%$. In group 2, the incidence of clot retention decreased two fold in comparison to traditional gravity-dependent bladder flow system. These changes were statistically significant $(P=0.001)$. We did not observe any adverse effects such as bladder perforation due to our high-pressure, high-flow system.

Conclusion: A pressurized irrigant system has better visualization during endourologic procedures, and prevents clot formation after open prostatectomy, TURP, and TURB without any adverse effects.

Keywords: cystoscopy, drainage, pressure, open prostatectomy, sphygmomanometer, transurethral lithotripsy, transurethral resection, prostate, bladder

\section{Introduction}

Three-way Foley catheters are used when irrigation of the bladder is anticipated to prevent or manage blood clots in the bladder. Effective bladder irrigation influences patient safety and clinical outcomes. ${ }^{1,2}$ Continuous bladder irrigation (CBI) is commonly used after transurethral resection of the prostate (TURP). The incidence of clot retention after TURP was reported to be $3.3 \%$ in a large, multicenter retrospective 
study. ${ }^{3}$ A high risk of postoperative bleeding, and thus clot retention, has been correlated with a greater size of the resected prostate, longer operative time, and positive preoperative urine culture. ${ }^{4-6} \mathrm{CBI}$ is also used for intravesical delivery of pharmacologic agents, such as amphotericin B irrigation for candida cystitis. ${ }^{7-9} \mathrm{CBI}$ with a 3-way Foley catheter is an important method of preventing and treating the hematuria associated with chemotherapy, vesical tumors, hemorrhagic cystitis, and radiation cystitis.

\section{Materials and methods}

In this 2-year prospective study conducted between March 2007 and April 2009, our new delivery system was used routinely for our admitted patients. Before this period, the traditional gravity system was used routinely for all 545 admitted cases, of which, 234 cases were underwent open prostatectomy, TURP, and transurethral resection of the bladder (TURB), and 311 cases underwent an endourologic procedure such as cystoscopy, ureteroscopy, or transurethral lithotripsy (TUL). In this system, a plastic connector was inserted into the irrigant bag with $1 \mathrm{~L}$ of normal saline, and its drainage terminal was connected to a Foley catheter or an endourologic instrument such as a cystoscope or ureteroscope. This system works only with gravity. It is clear that the drainage velocity of the irrigant fluid depends on the height of the irrigant bag.

The 831 eligible cases for our new system were divided into two groups who used our instrument in the same way in two situations: the first group underwent endourologic procedures such as cystourethroscopy, internal urethrotomy, and ureteroscopy, or some situations in the TUL procedures (458 cases); the second group used the system to increase flow rate and bladder irrigation after open prostatectomy, TURP, and TURB (373 cases). The duration of use for the new system depends on the severity of bleeding. When bleeding is increasingly severe, or for a more clear vision, we increased flow rate by hand pumping a sphygmomanometer bulb to increase pressure in the irrigant bag (Figures 1-3). This hand pumping is performed by the scrub nurse in the operating theater or recovery room. After clearing the drainage fluid, the irrigant system was changed to the gravity flow system. Analysis of data was performed with SPSS software (version 16; SPSS Inc, Chicago, IL).

\section{Results}

The major issue in the endourologic procedures is clear vision. This new system was used in 458 endourologic cases. We had two cases $(0.43 \%)$ of bloody or unclear vision

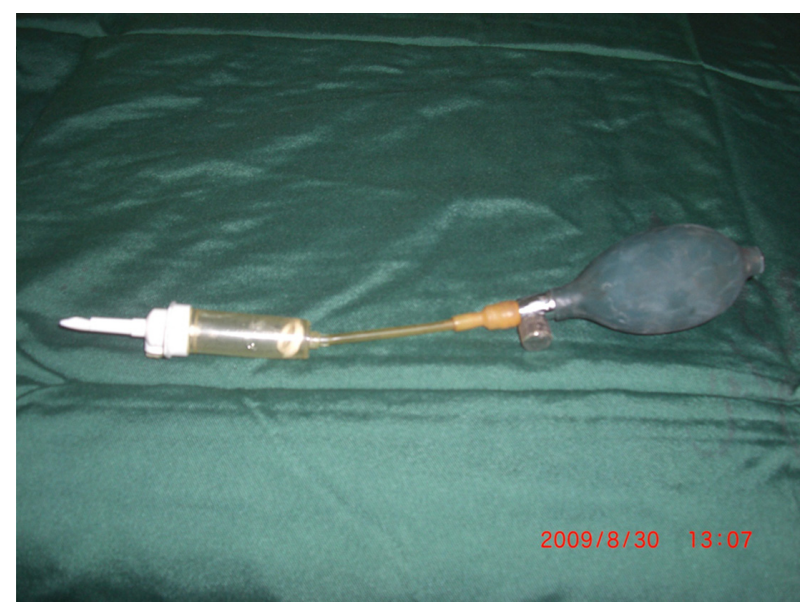

Figure I Pump with its connector.

in group 1, while in group $2 \mathrm{t}$ this problem was seen in 93 $(29.9 \%)$ of 311 cases. Clot retention episodes in group 2 decreased from 10 of 234 (4\%) to 6 of 321 (1.8\%) cases (Table 1). These differences were statistically significant $(P=0.001)$. The maximum and average flow rate of the system were evaluated. The gravity-dependent flow rate of an irrigant system suspended at $80 \mathrm{~cm}$ is $3 \mathrm{~mL} / \mathrm{sec}$, whereas with

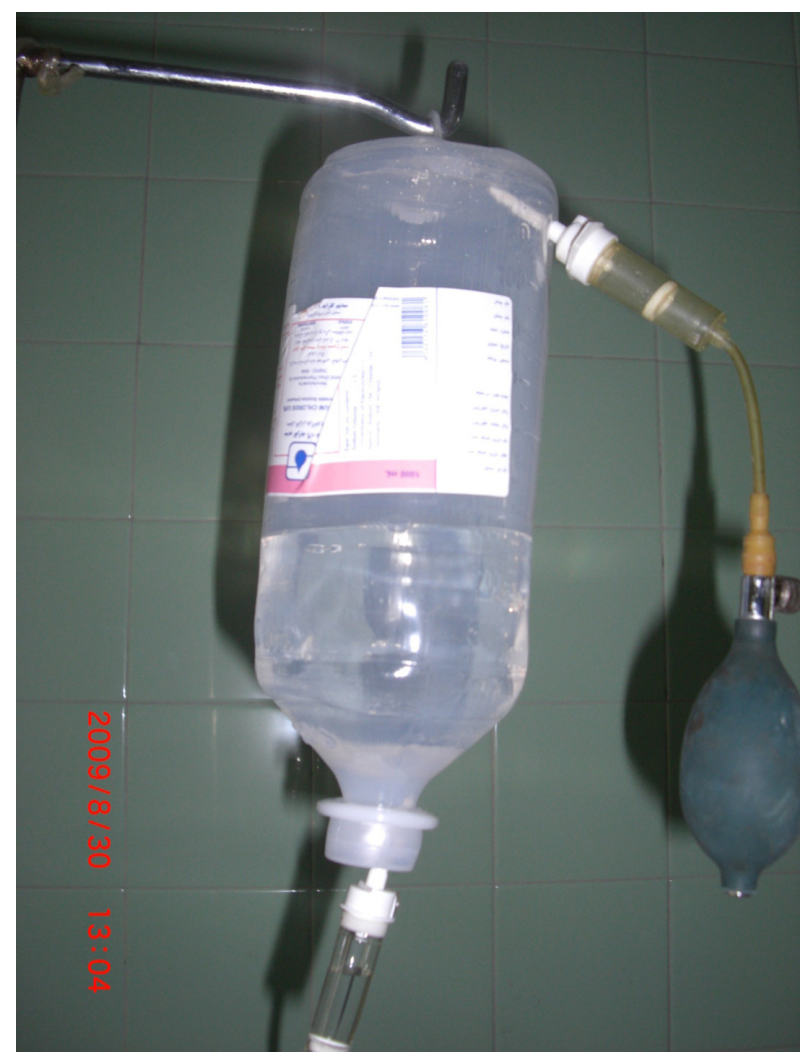

Figure 2 Pump and bulb connected to normal saline bag. 


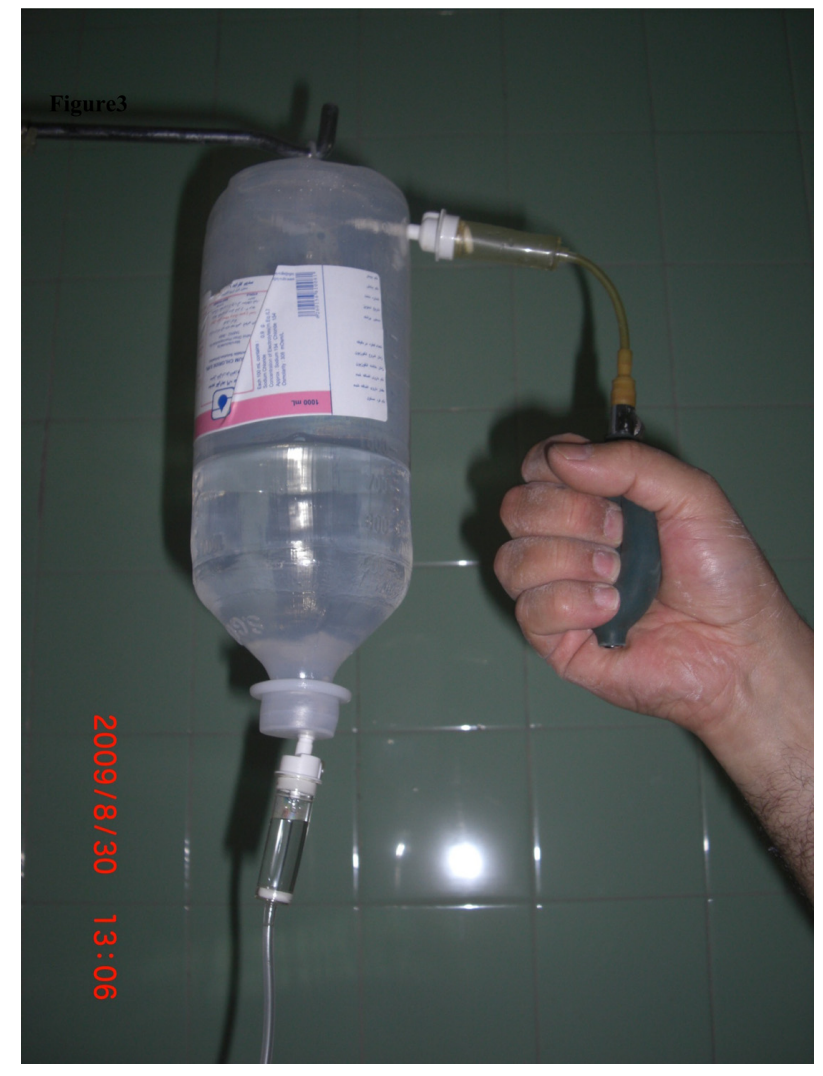

Figure 3 Hand pumping to increase pressure.

the use of our new delivery system the flow rate increased to $7.5 \mathrm{~mL} / \mathrm{sec}$ at maximal hand pressure.

\section{Discussion}

Using 3-way Foley catheters is an essential part of routine urological practice. They are available in different sizes: 20 , 22 , or $24 \mathrm{~F}$. In our daily practice and in the presence of significant bleeding, a size of $22 \mathrm{~F}$ catheter or greater is used. Three-way catheters require good irrigation and drainage flow characteristics to optimize a continuous flow system. All catheters with the size of 22 and $24 \mathrm{~F}$ have equivalent irrigation and drainage properties. The flow rate of the various 3-way catheters assessed is proportional to the size of the catheter when the drainage port is used for irrigation. This does not hold true when the irrigation channel is used.
Larger catheter size does not equate to better irrigation or drainage when continuous irrigation is performed. ${ }^{10}$ The disadvantage of 3-way catheters is that they provide a smaller lumen than do 2-way catheters. ${ }^{11}$ However, in a CBI system, the flow of irrigation should determine the drainage directly. For this reason, we designed a new high-flow, high pressure, hand pumped delivery system. Whitaker ${ }^{12}$ emphasized the flawed design of many available 3-way catheters, claiming that the input tube is compromised to achieve a wider output tube. He stressed that more efficient drainage is rooted in the irrigation flow rate because faster flow prevents blood clots from forming and accumulating in the bladder. Only small increases in the size of the irrigation lumen can double the irrigation flow rate without a significant decrease in the drainage tube lumen. As such, increases in flow are governed by Poiseuille's law, which states that there is a strong (fourth power) dependence of flow on the radius of the channel. Large-bore catheters are considered the best choice for effective removal of blood clots. ${ }^{13}$ Because 3 -way catheters establish a closed system with the bladder, drainage cannot be maximized if irrigation is severely lagging behind drainage. As such, it is meaningless to have good drainage properties if irrigation is insufficient. CBI typically takes place over the course of several hours or days, which makes average irrigation and drainage flow data more relevant than maximal flow data. ${ }^{2}$

\section{Conclusion}

The early hours after prostate surgery (TURP and open prostatectomy) are critical hours that need close observation because of bleeding and the risk of clot formation. Our new irrigation device generates superior flow in comparison to a traditional gravity-assisted irrigation system. This device is useful in situations in which efficient bladder irrigation is essential for patient safety. Our new device optimizes continuous bladder irrigation. It is an easily applicable system for bladder irrigation in patients with gross hematuria, and it may be used in remote or rural hospitals where special urologic equipment is not available.

Table I The number of our eligible cases before and after introducing our system, and the rate of its complications.

\begin{tabular}{|c|c|c|c|c|c|c|}
\hline & \multicolumn{2}{|c|}{ Number of cases } & \multicolumn{2}{|c|}{ Clot retention episodes } & \multicolumn{2}{|c|}{ Bloody or unclear field } \\
\hline & $\begin{array}{l}\text { Before our } \\
\text { new system }\end{array}$ & $\begin{array}{l}\text { After our } \\
\text { new system }\end{array}$ & Before & After & Before & After \\
\hline$\overline{\text { Group Ia }}$ & 311 & 458 & - & - & $93(29.9 \%)$ & $2(0.43 \%)$ \\
\hline Group $2^{b}$ & 234 & 321 & $10 / 234(4 \%)$ & $6 / 321(1.8 \%)$ & - & - \\
\hline
\end{tabular}

Notes: aCystoscopy, internal urethrotomy, and ureteroscopy cases; ' $\mathrm{O}$ pen prostatectomy, transurethral resection of the prostate, and transurethral resection of the bladders cases. 


\section{Disclosure}

Mojtaba Rajaei is the designer and inventor of the system.

\section{References}

1. Walton TJ, Heads S, Parkinson RJ, Griffiths TRL. An improvised delivery system for irrigation. Ann R Coll Surg Engl. 2008;90(5):429-430.

2. Braasch $\mathrm{M}$, Antolac $\mathrm{C}$, Hendlin $\mathrm{K}$, et al. Irrigation and drainage properties of three-way urethral catheters. Urology. 2006;67(1):40-44.

3. Mebust WK, Holtgrewe HL, Cockett AT, Peters PC. Transurethral prostatectomy: immediate and postoperative complications: a cooperative study of 13 participating institutions evaluating 3,885 patients. 1989. $J$ Urol. 2002;141:243-247.

4. Mobb GE, Farrar DJ: Is planned continuous irrigation indicated for haemorrhage following transurethral resection of the prostate? Br J Urol. 1993;71:707-710.

5. Olapade-Olaopa EO, Solomon LZ, Carter CJ, Ahiaku EK, Chiverton SG. Haematuria and clot retention after transurethral resection of the prostate: a pilot study. Br J Urol. 1998;82:624-627.

6. El Malik EM, Ibrahim AI, Gahli AM, Saad MS, Bahar YM. Risk factors in prostatectomy bleeding: preoperative urinary infection is the only reversible factor. Eur Urol. 2000;37:199-204.
7. Kauffman CA, Vazquez JA, Sobel JD, et al. Prospective multicenter surveillance study of funguria in hospitalized patients. The National Institute for Allergy and Infectious Diseases (NIAID) Mycoses Study Group. Clin Infect Dis. 2000;30:14-18.

8. Goldman HJ, Littman ML, Oppenheimer GD, et al. Monilial cystitiseffective treatment with instillations of amphotericin B. JAMA. 1960;174:359-362.

9. Jacobs LG, Skidmore EA, Freeman K, et al. Oral fluconazole compared with bladder irrigation with amphotericin B for treatment of fungal urinary tract infections in elderly patients. Clin Infect Dis. 1996;22:30-35.

10. Manikandan R, Selvaratnam V, Philip J, Hanlon A, Machin DG, Williamson M. Evaluation of flow characteristics of 3-way catheters. J Urol. 2009;181(4):1922-1925.

11. Cro DJ. A simpler method for continuous bladder irrigation. Urology. 1982;20:110.

12. Whitaker RH. A look at the three-way catheter. $B r J$ Urol. 1975;47:103.

13. Choong SKS, Walkden M, Kirby R. The management of intractable haematuria. BJU Int. 2000;86:951-959.
Therapeutics and Clinical Risk Management

\section{Publish your work in this journal}

Therapeutics and Clinical Risk Management is an international, peerreviewed journal of clinical therapeutics and risk management, focusing on concise rapid reporting of clinical studies in all therapeutic areas, outcomes, safety, and programs for the effective, safe, and sustained use of medicines. This journal is indexed on PubMed Central, CAS,

\section{Dovepress}

EMBase, Scopus and the Elsevier Bibliographic databases. The manuscript management system is completely online and includes a very quick and fair peer-review system, which is all easy to use. Visit $\mathrm{http}: / /$ www.dovepress.com/testimonials.php to read real quotes from published authors. 